\title{
Texture, microstructure and in-vitro starch digestibility of waxy rice cooked with hydrocolloids
}

\author{
*Srikaeo, K. and Paphonyanyong, W. \\ Faculty of Food and Agricultural Technology, Pibulsongkram Rajabhat University, Muang, Phitsanulok \\ 65000, Thailand
}

\begin{abstract}
Article history:
Received: 15 January 2020

Received in revised form: 3

March 2020

Accepted: 6 March 2020

Available Online: 26 March 2020
\end{abstract}

Keywords:

Waxy rice,

Guar gum,

Xanthan gum,

Sodium alginate,

Physicochemical property

DOI:

https://doi.org/10.26656/fr.2017.4(4).026

\begin{abstract}
Waxy rice which has been soaked in excessive water was cooked with hydrocolloid solutions, corresponding to hydrocolloid concentrations of $0.3,0.5$ and $0.7 \mathrm{~g} / 100 \mathrm{~g}$ rice. Hydrocolloids studied were guar gum (GG), xanthan gum (XG) and sodium alginate (SA). The hydrocolloid-cooked rice and the control sample, cooked in water without any hydrocolloid, were determined for their starch retrogradation, texture, microstructure and in-vitro starch digestion rate. It was found that hydrocolloid-cooked rice exhibited more retrograded starch than the control, providing high melting enthalpies. Retrograded starch caused the increased hardness of the cooked rice during storage, while adhesiveness and springiness tended to decrease. Although, hydrocolloid-cooked rice retrograded more during storage, it showed a lower hardness than the control sample due to the phase separation of hydrocolloids. SEM images revealed that intact starch was completely gelatinized. The control sample provided denser microstructure than the hydrocolloidcooked samples. While air cells were observed in the hydrocolloid-cooked samples especially with XG. The hydrocolloid-cooked rice exhibited lower starch digestion rate than the control. SA provided the lowest starch digestion rate, followed by GG and XG respectively
\end{abstract}

\section{Introduction}

Rice in the form of milled rice kernels is consumed as a staple food by almost half of the world population particularly in Asia which had high consumption and production. In Southeast Asia especially in northern and northeastern of Thailand, Laos, and some parts of Vietnam, people consume waxy rice, also called sticky or glutinous rice, as the main meal (Piyawanitpong et al., 2018). Milled rice is usually consumed as a cooked grain. Unlike non-waxy rice which can be cooked by boiling with water, waxy rice is usually cooked by steaming the pre-soaked waxy rice until it becomes fully cooked (soft and sticky texture). As starch is the major component in rice grain, changes in starch during cooking contribute to the cooked rice texture, and the most important changes are starch gelatinization and retrogradation (Perdon et al., 1999). Waxy rice starch consists almost entirely of amylopectin. The functional properties, as well as the texture of cooked waxy rice, are strongly related to the fine structure of amylopectin (Shi and Seib, 1992; Villareal et al., 1997; Jane et al., 1999; Ramesh et al., 1999; Bhattacharya, 2009; Zhu et al., 2010).
Freshly cooked waxy rice is soft, pliable and elastic in texture. However, their characteristics could change during storage as a consequence of various factors e.g. starch retrogradation, moisture loss, staling and increased firmness (Ji et al., 2007).

Through the process of retrogradation, the gelatinized starch is transformed from an amorphous state to a more ordered or crystalline state. Starch retrogradation occurs readily during the storage of heatprocessed starchy foods, as a spontaneous process reaching a metastable state of lower free energy. Retrogradation, however, often exerts unacceptable influences on the texture of starchy foods (Charoenrein and Udomrati, 2013), such as in staling of bread and hardening of rice cake (Chung et al., 2006). However, it has been reported that starch retrogradation could result in a reduction of the glycemic index (GI), due to the increased resistance to digestive enzymes (Eerlingen et al., 1994; Frei et al., 2003). Cooked rice is rapidly digested, and therefore the GI of freshly cooked rice is known to be relatively high among various starchy foods (Chung et al., 2007). 
Hydrocolloids are widely used as food additives to improve stability and textures (Arranz-Martínez et al., 2014). They have been reported to retard starch retrogradation in various starches and cereal products e.g. wheat starch (Zhou et al., 2008), maize starch (Fu and BeMiller, 2017), bread (Anton and Artfield, 2008; Davidou et al., 1996) and rice cakes (Turabi et al., 2008). Most hydrocolloids are readily soluble in water but rarely digested in human upper intestines, thus providing the same physiological effects as dietary fibers (Viebke et al., 2014; Li and Nie, 2016). As starch of cooked waxy rice can be easily digested and their textures become harder during storage, hydrocolloids may help to improve the texture and starch digestibility. Therefore, this study aimed to investigate the effects of various hydrocolloids on the texture and digestibility of cooked waxy rice. Moreover, most of the previous works usually used rice starch or flour, this study investigates the cooked intact rice grain.

\section{Materials and methods}

\subsection{Materials}

Waxy rice ( $\mathrm{RD} 6$ variety) harvested during November 2018 was obtained from Phitsanulok Rice Research Center (Thailand). The paddy was milled using the pilot milling unit (NW 100, Natrawee Technology Co., Ltd. Thailand). The rice sample $(500 \mathrm{~g})$ was passed through dehusk equipment with rubber rollers to remove the husk and then it was passed over an abrasive cone to produce white rice. The polished white rice was stored at $4^{\circ} \mathrm{C}$ before used.

Three food-grade hydrocolloids, including guar gum (GG), xanthan gum (XG) and sodium alginate (SA) were obtained from Union Science Co., Ltd. (Thailand). All chemicals and enzymes were analytical grade and purchased from Sigma-Aldrich (Thailand) Co., Ltd.

\subsection{Sample preparation}

Waxy rice (polished white rice) was soaked in excessive distilled water for $12 \mathrm{hrs}$ at room temperature and the water was then discarded. The soaked waxy rice was mixed with the hydrocolloid solution, corresponding to each hydrocolloid concentration of $0.3,0.5$ and 0.7 $\mathrm{g} / 100 \mathrm{~g}$ rice. To facilitate the solubility, hydrocolloids at the desired amount were dissolved in $25 \mathrm{~mL}$ distilled water before mixing with waxy rice in the $50 \mathrm{~mL}$ beaker. The rice samples mixed with hydrocolloids were steamed for 25 mins using the electric steamer (Tefal Model VC1006) until the rice is fully cooked, as evidenced by visual inspection (no white core in the cooked waxy rice kernels).

\subsection{Starch retrogradation}

Starch retrogradation properties were analyzed by a differential scanning calorimeter (DSC). The DSC (DSC 1, Mettler Toledo, USA) equipped with a refrigerated cooler was used. Freshly and stored cooked rice samples were ground using the universal high-speed smashing machines (FW80-1, Tianjin Taisite Instrument Co. Ltd., China). The moisture content of the ground samples was adjusted to $70 \%$ wet basis (if needed) by adding distilled water. The samples were accurately weighed $(20 \pm 5 \mathrm{mg})$ into aluminum DSC pans $(100 \mu \mathrm{L})$ and hermetically sealed. The sealed pans were kept at $4^{\circ} \mathrm{C}$ and taken for DSC analysis at 0,5 and 10 days. The DSC analysis was run by scanning from $25-120^{\circ} \mathrm{C}$, ramping at $10^{\circ} \mathrm{C} / \mathrm{min}$ and a hermetically sealed empty pan was used as a reference, with nitrogen used as a purging gas. The software used for the analysis of the resulting thermograms was Star $^{\mathrm{e}}$ software (ver. 9.20, Mettler Toledo, USA). The endothermic transition associated with the retrograded starch melting peak appearing between $45-80^{\circ} \mathrm{C}$ was recorded. The enthalpy of transition was estimated from the integrated heat flow over the temperature range of the transition.

\subsection{Texture analysis}

The texture was examined for freshly cooked rice and during storage at room temperature $(0,6,12,18$ and $24 \mathrm{hrs}$ ), in order to monitor the staling, using the method as described elsewhere (Chung et al., 2007) with some modifications. Briefly, five kernels of cooked rice were randomly selected and placed on the sample plate of a texture analyzer (TA-XT2, Stable Micro Systems, UK). A texture profile analysis (TPA) mode was selected employing a cylinder-type plunger (20 mm diameter), a crosshead speed of $0.5 \mathrm{~mm} / \mathrm{sec}$ at a strain of $50 \%$. Five replicates from different sets of cooked rice kernels were tested.

\subsection{Microstructure}

Microstructure of the dried-cooked rice grains was examined by SEM (JEOL JSM-5910LV, JOEL USA Inc.). Cooked rice samples were dehydrated using the laboratory freeze dryer (Lyovapor ${ }^{\mathrm{TM}}$ L-200, BÜCHI Labortechnik AG, Switzerland). The dried specimens were placed on the sample holder with the help of a double-sided scotch tape and sputter-coated with gold (2 mins, 2 mbar) before transferred to the SEM microscope.

\subsection{In-vitro starch digestibility}

In-vitro starch digestion, based on the simulated small intestinal digestion, was conducted using the method described earlier (Minekus et al., 2014) with some modifications. Simulated intestinal fluid (SIF) was 
composed of $6.8 \mathrm{~mL}$ of $0.5 \mathrm{M} \mathrm{KCl}, 0.8 \mathrm{~mL}$ of $0.5 \mathrm{M}$ $\mathrm{KH}_{2} \mathrm{PO}_{4}, 42.5 \mathrm{~mL}$ of $1 \mathrm{M} \mathrm{NaHCO}_{3}, 9.6 \mathrm{~mL}$ of $2 \mathrm{M}$ $\mathrm{NaCl}$, and $1.1 \mathrm{~mL}$ of $0.15 \mathrm{M} \mathrm{MgCl}_{2}\left(\mathrm{H}_{2} \mathrm{O}\right)_{6}$ in $400 \mathrm{~mL}$ of distilled water. Pancreatin was diluted 1:5 (w/v) with SIF and centrifuged at $3000 \times g$ for 20 mins. The enzyme solution was prepared by dilution of $5 \mathrm{~mL}$ of pancreatin supernatant, $0.435 \mathrm{~g}$ of bile extract, and $2 \mathrm{~mL}$ of SIF. Cooked rice samples were ground using a motar, simulating the mouth chewing. The ground samples $(0.5$ g) were mixed with $26 \mathrm{~mL}$ of prepared SIF, $40 \mathrm{uL}$ of 0.3 $\mathrm{M} \mathrm{CaCl}_{2}, 0.15 \mathrm{~mL}$ of $1 \mathrm{M} \mathrm{NaOH}$, and $1.31 \mathrm{~mL}$ of distilled water. After the addition of enzyme solution and amyloglucosidase $(0.2 \mathrm{~mL}$ per gram of starch in the sample), the $\mathrm{pH}$ of the sample was adjusted to 6.0 using $1 \mathrm{M} \mathrm{HCl}$, and the sample was incubated in a $37^{\circ} \mathrm{C}$ shaking water bath. Aliquots of $0.1 \mathrm{~mL}$ were withdrawn at $0,30,60,90,120$, and 180 mins during digestion. Each aliquot was replaced with $1.4 \mathrm{~mL}$ of absolute ethanol and centrifuged at $3000 \times \mathrm{g}$ for 3 mins. The released glucose content of the supernatant was analyzed using the GOPOD kit (Megazyme International Ireland Ltd., Wicklow, Ireland). Results were expressed as percentage of starch hydrolyzed using the following equation:

$$
\text { Digested } \operatorname{starch}(\%)=0.9 \times G_{r} / S_{i}
$$

Where $G_{r}$ is the amount of glucose released, and $S_{i}$ is the initial amount of starch. A conversion factor of 0.9 , which is generally calculated from the molecular weight of starch monomer/molecular weight of glucose $(162 / 180=0.9)$, was use (Goñi et al., 1997).

\subsection{Statistical analysis}

All values are expressed as means \pm standard deviations from at least triplicated data. Analysis of variance (ANOVA) and test of significance were performed using Minitab ${ }^{\circledR}$ ver. 18 with confidence level of $95 \%$. The samples were randomized for all the analyses described above.

\section{Results and discussion}

\subsection{Starch retrogradation}

Starch retrogradation enthalpy of cooked waxy rice samples stored from $0-10$ days was investigated by a DSC and the results are shown in Table 1.

A typical peak representing the melting of retrograded amylopectin was detected and the onset, peak and conclusion temperature ranged from $45-82^{\circ} \mathrm{C}$ (data not shown). The starch retrogradation enthalpy values increased with storage time, consistent with increasing amounts of retrograded amylopectin. This pattern is observed in all samples. It was found that the control sample (waxy rice cooked without any hydrocolloid) exhibited less retrograded amylopectin (smaller enthalpies) compared to the hydrocolloidcooked rice samples (Table 1). Comparing among all hydrocolloids used, the retrogradation enthalpies of the same storage time were similar and the concentrations $(0.5 \%$ and $1.0 \%)$ did not strongly affect the enthalpy values. XG provided higher values than those obtained from the other hydrocolloids, except at 10 days in which SA seemed to give higher values than the others.

Table 1. Starch retrogradation enthalpy of the cooked waxy rice samples stored from $0-10$ days at $4^{\circ} \mathrm{C}$

\begin{tabular}{lccc}
\hline \multirow{2}{*}{\multicolumn{1}{c}{ Samples }} & \multicolumn{3}{c}{$\begin{array}{c}\text { Starch retrogradation enthalpy } \\
(\mathrm{J} / \mathrm{g} \text { dry sample })\end{array}$} \\
\cline { 2 - 4 } & 0 day & 5 days & 10 days \\
\hline Control & $0.22 \pm 0.02^{\mathrm{e}}$ & $0.54 \pm 0.02^{\mathrm{c}}$ & $1.53 \pm 0.05^{\mathrm{d}}$ \\
Guar gum 0.5\% & $0.32 \pm 0.01^{\mathrm{cd}}$ & $1.85 \pm 0.03^{\mathrm{a}}$ & $2.46 \pm 0.12^{\mathrm{c}}$ \\
Guar gum 1.0\% & $0.30 \pm 0.01^{\mathrm{d}}$ & $1.91 \pm 0.02^{\mathrm{a}}$ & $2.59 \pm 0.06^{\mathrm{c}}$ \\
Xanthan gum 0.5\% & $0.43 \pm 0.02^{\mathrm{ab}}$ & $1.69 \pm 0.07^{\mathrm{ab}}$ & $2.89 \pm 0.01^{\mathrm{b}}$ \\
Xanthan gum 1.0\% & $0.47 \pm 0.01^{\mathrm{a}}$ & $1.65 \pm 0.03^{\mathrm{ab}}$ & $2.99 \pm 0.02^{\mathrm{ab}}$ \\
Alginate 0.5\% & $0.36 \pm 0.03^{\mathrm{bcd}}$ & $1.47 \pm 0.11^{\mathrm{b}}$ & $3.16 \pm 0.06^{\mathrm{a}}$ \\
Alginate 1.0\% & $0.40 \pm 0.02^{\mathrm{abc}}$ & $1.50 \pm 0.13^{\mathrm{b}}$ & $3.07 \pm 0.10^{\mathrm{ab}}$ \\
\hline
\end{tabular}

Values are mean \pm standard deviation $(n=3)$. Means with different letters in the same column are significantly different at $\mathrm{p}<0.05$.

The more intact granules and ordered structure of starch in hydrocolloid-cooked waxy rice are proposed to result in larger DSC enthalpies than the control (Ai et al., 2018). However, from the texture analysis results (Figure 1), the rice samples cooked with hydrocolloids showed a lower hardness than the control sample. This suggests that amylopectin retrogradation may not be solely responsible for the hardness of the cooked waxy rice. The anti-firming action of the hydrocolloids could have another origin. It is probably related to the phase separation theory (Appelqvist and Debet, 1997). Hydrocolloids may form a continuous soft phase with water, which separates from a second phase made of stiffened starch granules. The balance of these two phases may affect the hardness of the cooked waxy rice. Possibly the soft hydrocolloid-water phase is dominant and yields the softer cooked rice texture as found in this study. A similar phenomenon has been recently reported in steamed-rice cake in which alginate formed a continuous phase with water, whereas the partially gelatinized starch granules were an included phase distributed within the continuous phase. The reduced hardness of aged rice cakes with alginate is more dependent on the soft continuous phase than the hard starch granules, therefore leading to a softer texture (Ai et al., 2018). Moreover, hydrocolloids are macromolecule which is unlikely to be able to penetrate either intact starch granules or swollen granules (Appelqvist and Debet, 1997). In addition, hydrocolloids 
used in this study absorbed water first as they were predissolved prior to cooking with the rice grains. Therefore, less water would be available for starch granule swelling due to competitiveness with the hydrocolloids (Gonera and Cornillon, 2002; Ramírez et al., 2015).
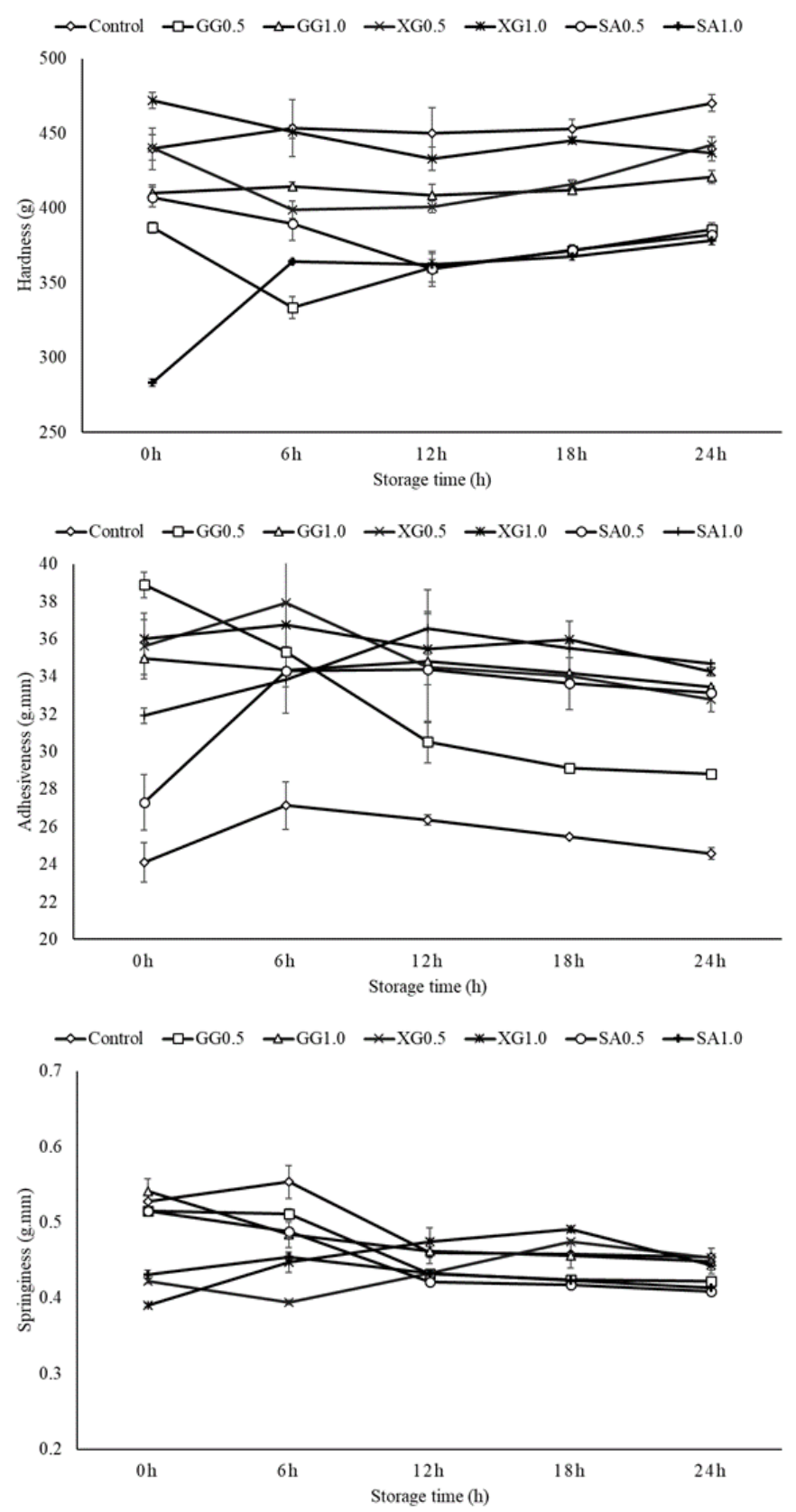

Figure 1. Hardness, adhesiveness and springiness of the cooked waxy rice samples during storage at room temperature for $24 \mathrm{hrs}$.

Control $=$ Cooked without any hydrocolloid, GG0.5 $=$ Cooked with $0.5 \%$ guar gum, GG1.0 = Cooked with $1.0 \%$ guar gum, XG0.5 $=$ Cooked with $0.5 \%$ xanthan gum, XG1.0 = Cooked with $1.0 \%$ xanthan gum, SA $0.5=$ Cooked with $0.5 \%$ sodium alginate, SA1.0 $=$ Cooked with $1.0 \%$ sodium alginate.

\subsection{Texture}

Hardness, adhesiveness and springiness of the freshly cooked rice and changes of textural properties during storage at room temperature for $24 \mathrm{hrs}$ are shown in Figure 1.

Generally, cooked rice samples increased its hardness when stored for a longer period. This phenomenon was observed in both the control (cooked without any hydrocolloid) and hydrocolloid-cooked rice samples. However, the hardness of the control sample was higher than that of the hydrocolloid-cooked rice. This trend was found in all concentrations tested $(0.5 \%$ and $1.0 \%$ ). Comparing among all hydrocolloids, GG and SA provided lower hardness values than XG. Therefore, it is suggested that hydrocolloids improved the texture of cooked rice samples in both freshly and stored samples by prolonging the soft texture of cooked waxy rice. Hardness is usually used as the indicator for starch retrogradation. As discussed earlier in the starch retrogradation section, melting enthalpies of the control sample were found to be lower than those of the hydrocolloid-cooked rice samples (refers Table 1). This indicated that the control sample retrograded slower than the hydrocolloid-cooked rice samples. However, their hardness values were higher. We assumed this could be caused by phase separation as hydrocolloids might form a continuous soft phase with water, and separate from a second phase made of stiffened starch granules. The soft hydrocolloid-water phase was dominant and prolonged the soft cooked rice texture.

For adhesiveness and springiness, similar trend was observed. The values tended to decrease as the storage time increased. The difference is that the control sample exhibited lower adhesiveness values while it showed higher springiness values than those of the hydrocolloidcooked rice samples. Waxy rice is usually sticky when it is fully cooked and thus its adhesiveness is high. Hydrocolloids formed a continuous soft phase with water and covered the rice grain surface. Consequently, this retarded sticky properties of the cooked waxy rice and thus the adhesiveness was low. In terms of springiness, both the control and hydrocolloid-cooked rice samples provided similar results and trends. The springiness values of the control and hydrocolloid-cooked rice samples were found to be not significantly different ( $p>0.05)$, numerical data not shown. The values seemed to be slightly decreased over the storage time.

Hydrocolloids have been widely used in food products to modify texture, improve moisture retention, control water mobility and maintain overall product quality during storage. Nevertheless, the properties of the hydrocolloids vary in a great extent depending on their origin and chemical structure. Most of the published articles used hydrocolloids in rice flour/starch products (Srikaeo et al., 2018) and very few papers have addressed the use of hydrocolloids in the intact rice 
grains. One reported that hydrocolloids affected the texture of cooked rice and the results depended on hydrocolloid types (Chung et al., 2007). They found that xanthan gum, gellan gum, sodium alginate, locust bean gum and arabic gum made the cooked rice harder, and hardness was increased with higher concentrations of hydrocolloids. However, mixed data were obtained for adhesiveness and springiness. Increased springiness values for cooked rice were observed by adding hydrocolloids at the low level. Opposite results (decreased springiness) were found when adding hydrocolloids at a high level. Hydrocolloids affected the adhesiveness of cooked rice in a similar manner to the springiness. They concluded from the texture data that the surface of the cooked rice became stickier and more elastic (higher springiness) when a low level of hydrocolloids was added. However, excess hydrocolloids made the cooked rice less sticky and less elastic (Chung et al., 2007).

Staling of starchy foods is typically associated with the increase in compressive hardness due to starch retrogradation and redistribution of moisture (Ai et al., 2018). In this study, the increase of hardness in cooked waxy rice is probably due to staling and starch retrogradation. The use of hydrocolloids delayed the increase of hardness when compared to the control sample (Figure 1). In contrast to this study, hydrocolloids were reported to increase the hardness of intact cooked rice and the cause was due to the interactions between the hydrocolloids and starch. It was proposed that hydrocolloids might coat the surface or fill the cracks inherent in the rice kernels and thus retard the leaching of starch chains during cooking. Also, hydrocolloids in the cracks could limit water penetration and thus the cooked rice kernels showed increased hardness (Chung et al., 2007). However, in this study, as the rice has been soaked with water before cooking, we assumed that water has been penetrated inside the cracks as well as in the rice kernels. During cooking, starch had sufficient water for gelatinization. While hydrocolloids absorbed water, formed the soft continuous phase with water, and coated the surface of the cooked rice. Effects of water holding capacity of the hydrocolloids that coated the rice kernels might help to reduce the hardness values of the cooked rice when compared to the control sample. All hydrocolloids used in this study also exhibited antistaling properties by delaying the rate of hardness increase in the cooked rice samples when compared to the control (Figure 1). SA was found to be the best in terms of anti-staling properties. It should be noted that the effects of anti-staling of hydrocolloids in starchy foods are dependent on moisture content. Anti-staling agents function by different mechanisms in high moisture starchy foods than for the low moisture food systems (Ai et al., 2018). The cooked waxy rice in this study is considered a high moisture food.

\subsection{Microstructure}

SEM images of the rice samples cooked with different hydrocolloids as well as the control sample are shown in Figure 2. Notably that the SEM images were observed in freshly cooked rice only, not in stored rice. The images shown here are taken from the control and hydrocolloid-cooked rice sample at $0.5 \%$ of hydrocolloid used. The SEM images of the other samples provided a similar trend and therefore they are not shown here.

From Figure 2, it can be seen that all longitudinal and transverse sections of the samples, both the control and hydrocolloid-cooked rice samples, showed the mudlike or fused-mass structure. This occurred as a result of completely gelatinized starch (Srikaeo et al., 2006) together with the disrupted protein bodies occupied all the air spaces in the endosperm. The hydrothermal treatment during cooking caused irreversible swelling and fusion of fully starch granules, resulted together with the transformation of the crystalline form of starch into an amorphous form. Thus, the orderly polyhedral structure of compound starch granules changed into a coherent mass (Chandrasekhar and Chattopadhyay, 1990).

Previous works on the microstructure of rice mixed with hydrocolloids were usually in the form of rice starch or flour products, with scarce literature on the grain kernels. In this study, as the rice kernels were soaked in water before cooking and the hydrocolloids were dissolved before mixing with the soaked rice kernels. During cooking, hydrocolloids absorbed water while starch gelatinized. As mentioned earlier, hydrocolloids are macromolecule which is unlikely to be able to penetrate either intact starch granules or swollen granules (Appelqvist and Debet, 1997). Thus, we assumed that the interactions between hydrocolloids and starch granules were minimal during cooking. In addition, the surface of the cooked rice (longitudinal sections) of the hydrocolloid-cooked samples was found to be smoother than that of the control. This indicated that the hydrocolloids could cover all the other layer during cooking (Figure 2).

Rice grains naturally contain fine cracks throughout the endosperm. Cooked grains also contain cracks in the starchy endosperm which appear similar to those in the raw grains. The cracks serve as channels for the flow of water into the grain during cooking. Two types of structures are evident in the cooked grains: those where the starchy endosperm remains intact and those containing voids in the central endosperm (Ogawa et al., 

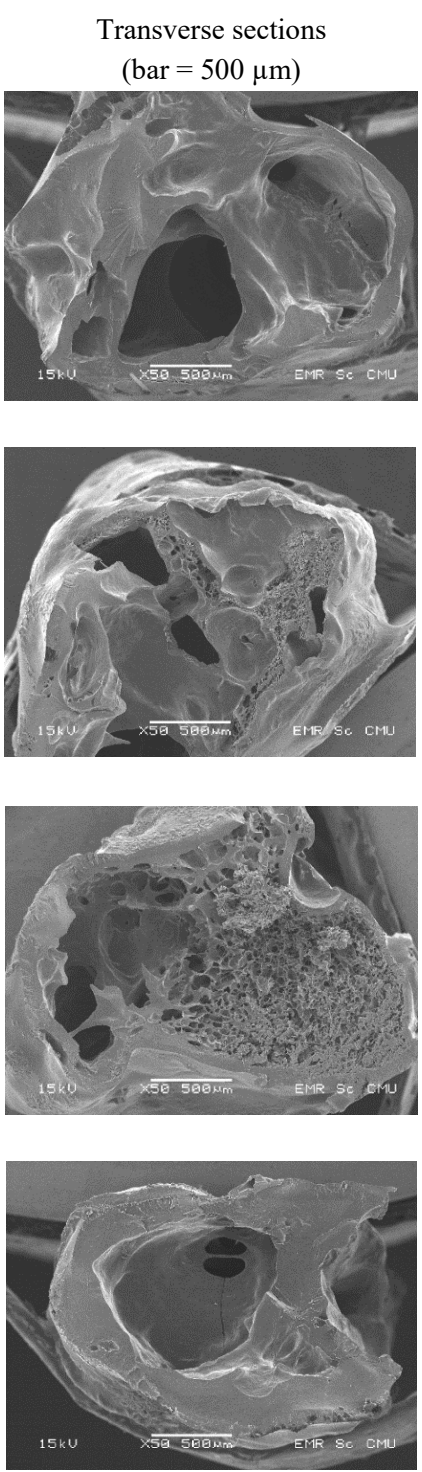

Transverse sections $($ bar $=100 \mu \mathrm{m})$

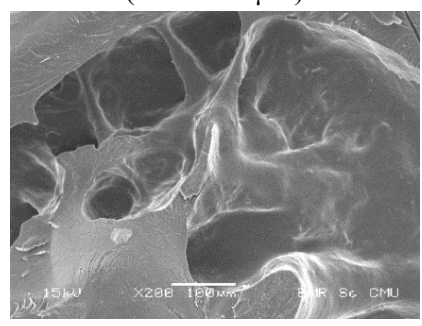

Cooked rice control samples

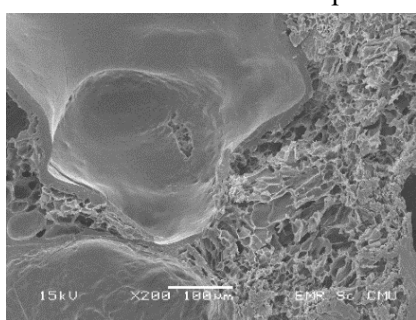

Cooked rice with guar gum

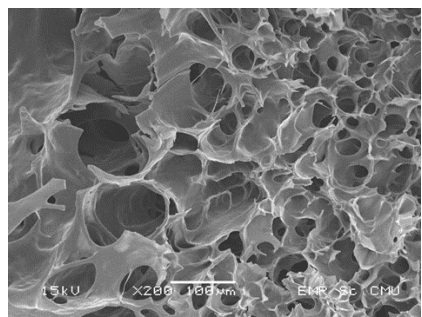

Cooked rice with xanthan gum

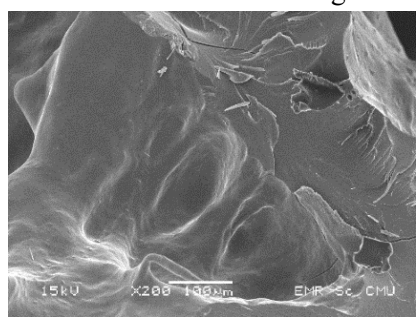

Cooked rice with sodium alginate
Longitudinal sections (bar $=500 \mu \mathrm{m})$
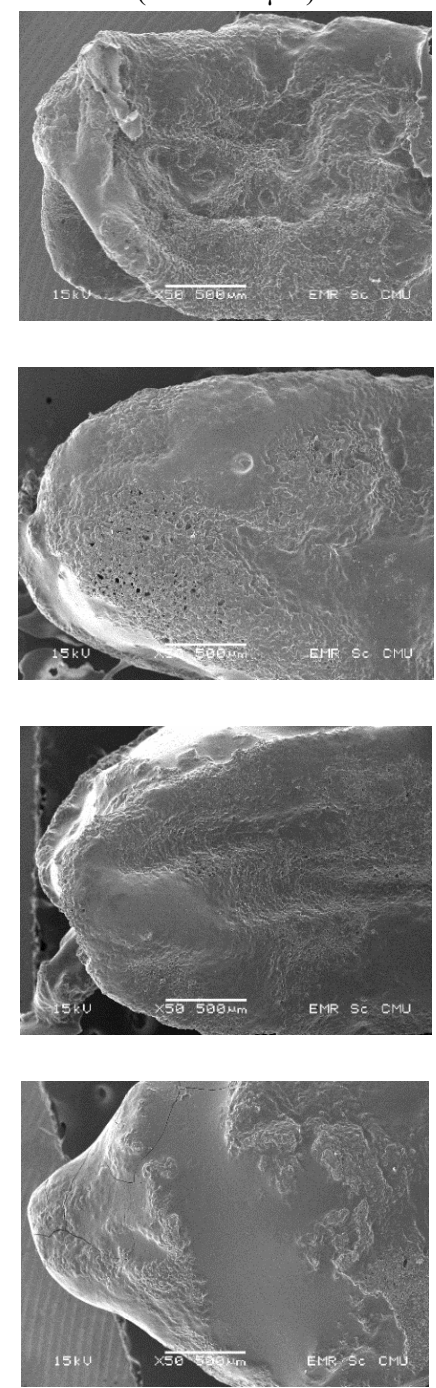

Figure 2. SEM images of the cooked waxy rice samples.

2003). The voids or internal hollows in the cooked grains account for most of the deformation and swelling of the grain during cooking and are probably the result of rapid pressure buildup (steaming) and subsequent expansion or localized explosion within the grain (Horigane et al., 2000).

In this study, the voids are clearly seen in both the control and hydrocolloid-cooked samples, as observed by the transverse sections in SEM images. The control sample provided denser microstructure than the hydrocolloid-cooked samples. While air cells were observed in the hydrocolloid-cooked samples especially with XG, followed by $\mathrm{GG}$ and SA. Among all hydrocolloids, SA provided the denser microstructure than the others. During cooking, hydrocolloids absorbed water and coated the outer layer of the rice kernels, while some could fill up the cracks. Starch in the intact grains gelatinized using water, the majority from which it absorbed during the soaking process. Excessive water from the hydrocolloid-water solutions used for cooking, after being absorbed by the hydrocolloids, may be available to aid the starch gelatinization but it should be limited. This scenario that limits the water availability in hydrocolloid-cooked rice samples may result in the porous microstructure when compared to the control (Figure 2). Different properties of hydrocolloids especially the shear-thinning character of xanthan gum which is more pronounced than those of guar gum and sodium alginate (García-Ochoa et al., 2000) may cause the more porous microstructure in cooked rice. In addition, the dense microstructure observed in the control sample may result from the completed starch gelatinization with excessive water, giving the dense mud-like structure.

\subsection{In-vitro starch digestibility}

Figure 3 shows the starch digestogram of the cooked rice samples. Notably that the in-vitro starch digestion rate was conducted for freshly cooked rice only, not in stored rice.

In general, the hydrocolloid-cooked rice samples exhibited lower starch digestion rate than the control. 
Percentage of digested starch of the control sample reached almost $100 \%$ at the end of the test period $(180$ $\mathrm{min})$. While the final digested starch of the hydrocolloidcooked rice samples ranged from $62-90 \mathrm{~g} / 100 \mathrm{~g}$ dry sample. Comparing among all hydrocolloids used, SA exhibited the lowest starch digestion rate, followed by GG and XG respectively. With the same hydrocolloid, higher concentration, $1.0 \%$, provided lower starch digestion rate (Figure 3). It is summarized in this study that cooking rice with hydrocolloids provided benefits in terms of decreased starch digestion rate and this could contribute to the reduced GI of the cooked rice.

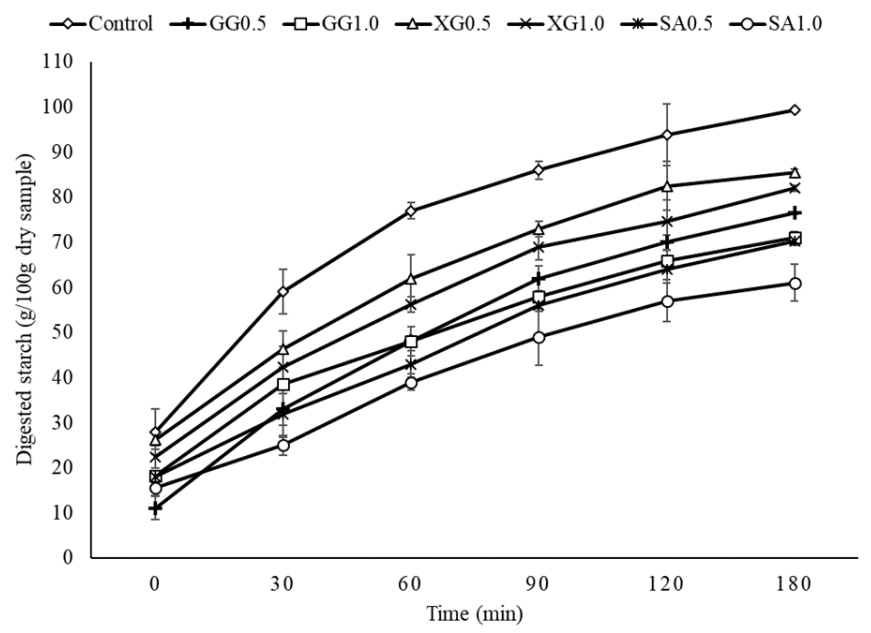

Figure 3. Starch digestogram of the cooked waxy rice samples. Control $=$ Cooked without any hydrocolloid, GG0.5 = Cooked with $0.5 \%$ guar gum, GG1.0 = Cooked with $1.0 \%$ guar gum, XG0.5 = Cooked with 0.5\% xanthan gum, XG1.0 = Cooked with $1.0 \%$ xanthan gum, SA0.5 = Cooked with $0.5 \%$ sodium alginate, SA1.0 $=$ Cooked with $1.0 \%$ sodium alginate.

The effects of various hydrocolloids on starch digestibility of cooked rice have been previously investigated (Chung et al., 2007), observing that the enzymatic digestion pattern changed in the presence of hydrocolloids. However, no clear trend could be established because the global effect on the starch digestion fractions was largely dependent on the hydrocolloid type. The impact also varied depending on the starch origin and food type (Srikaeo et al., 2018). It has been reported that hydrocolloids could either decrease or increase starch digestion rate in noodles made with various cereal flours (Jang et al., 2015). Most of the published papers suggested that hydrocolloids could retard starch digestion rate in food systems e.g. SA in rice dough (Koh et al., 2009) and arabic gum in highamylose rice noodles (Bae et al., 2019) and in mixed grain porridge ( $\mathrm{Hu}$ et al., 2014). Although, some suggested that hydrocolloids could increase the rate of starch digestion in fermented rice noodles (Srikaeo et al., 2018).

The mechanisms have been proposed that hydrocolloids could inhibit the enzymatic hydrolysis by different ways, either single or a combined effect, e.g. work as a barrier to enzyme access to starch granules, encapsulate starch granule and preventing enzyme attack, increase the slowly digestible starch fraction in the food systems, inhibit starch from accessing the water in the food systems, restrict the water in starchy foods, increase the viscosities of digesta, or restrict the accessibility of the digestive enzymes (Chung et al., 2007; Roberts, 2011; Fabek et al., 2014; Jung et al., 2017).

\section{Conclusion}

The texture of cooked waxy rice changes during storage because of various factors e.g. starch retrogradation, moisture loss, staling and increased firmness. Hydrocolloids have been used as additives in various food products. The application of hydrocolloids in intact grains is very scarce in the literatures. This study cooked waxy rice with three hydrocolloids (GG, $\mathrm{XG}$ and SA). The findings suggested that hydrocolloidcooked waxy rice exhibited more retrograded starch than the control rice sample. However, hydrocolloids improved the texture of cooked waxy rice by prolonging the soft texture during storage and delayed the starch digestion rate. Notably that the effects of hydrocolloids depend greatly on the type of hydrocolloids. The information obtained from this study could help to understand the changes of physicochemical properties of cooked waxy rice and consequently provide benefits for designing proper processes or products from waxy rice.

\section{Conflict of Interest}

The authors declare no conflict of interest.

\section{Acknowledgments}

This study was financially supported by the Thailand Science Research and Innovation, formerly known as the Thailand Research Fund (TRF-RRI Grant No. MSD61I0013). The cooperation from the industrial partner is greatly acknowledged.

\section{References}

Ai, J., Witt, T., Cowin, G., Dhital, S., Turner, M.S., Stokes, J. R. and Gidley, M.J. (2018). Anti-staling of high-moisture starchy food: Effect of hydrocolloids, emulsifiers and enzymes on mechanics of steamedrice cakes. Food Hydrocolloids, 83, 454-464. https:// doi.org/10.1016/j.foodhyd.2018.05.028

Anton, A.A. and Artfield, S.D. (2008). Hydrocolloids in gluten-free breads: A review. International Journal of Food Sciences and Nutrition, 59(1), 11-23. https:// 
doi.org/10.1080/09637480701625630

Appelqvist, I.A.M. and Debet, M.R.M. (1997). Starchbiopolymer interactions - A review. Food Reviews International, 13(2), 163-224. https:// doi.org/10.1080/87559129709541105

Arranz-Martínez, P., Srikaeo, K. and González-Sánchez, A.L. (2014). Effects of non-starch polysaccharides on physicochemical properties and in vitro starch digestibility of rice starches. Bioactive Carbohydrates and Dietary Fibre, 4(1), 6-15. https:// doi.org/10.1016/j.bcdf.2014.06.002

Bae, I.Y., Oh, I.K., Jung, D.S. and Lee, H.G. (2019). Influence of arabic gum on in vitro starch digestibility and noodle-making quality of Segoami. International Journal of Biological Macromolecules, 125, 668-673. https://doi.org/10.1016/ j.ijbiomac.2018.12.027

Bhattacharya, K.R. (2009). Physicochemical basis of eating quality of rice. Cereal Foods World, 54(1), 18 -28. https://doi.org/10.1094/CFW-54-1-0018

Chandrasekhar, P.R. and Chattopadhyay, P.K. (1990). Studies on microstructural changes of parboiled and puffed rice. Journal of Food Processing and Preservation, 14(1), 27-37. https://doi.org/10.1111/ j.1745-4549.1990.tb00123.x

Charoenrein, S. and Udomrati, S. (2013). Retrogradation of waxy rice starch gel in the vicinity of the glass transition temperature. International Journal of Food Science, 2013, $549192 . \quad$ https:// doi.org/10.1155/2013/549192

Chung, H.J., Lim, H.S. and Lim, S.T. (2006). Effect of partial gelatinization and retrogradation on the enzymatic digestion of waxy rice starch. Journal of Cereal Science, 43(3), 353-359. https:// doi.org/10.1016/j.jcs.2005.12.001

Chung, H.J., Liu, Q. and Lim, S.T. (2007). Texture and in vitro digestibility of white rice cooked with hydrocolloids. Cereal Chemistry, 84(3), 246-249. https://doi.org/10.1094/CCHEM-84-3-0246

Davidou, S., Le Meste, M., Debever, E. and Bekaert, D. (1996). A contribution to the study of staling of white bread: Effect of water and hydrocolloid. Food Hydrocolloids, 10(4), 375-383. https:// doi.org/10.1016/S0268-005X(96)80016-6

Eerlingen, R.C., Jacobs, H. and Delcour, J. (1994). Enzyme-resistant starch. 5. Effect of retrogradation of waxy maize starch on enzyme susceptibility. Cereal Chemistry, 71, 351-355.

Fabek, H., Messerschmidt, S., Brulport, V. and Goff, H.D. (2014). The effect of invitro digestive processes on the viscosity of dietary fibres and their influence on glucose diffusion. Food Hydrocolloids,
35, $\quad$ 718-726.

j.foodhyd.2013.08.007

https://doi.org/10.1016/

Frei, M., Siddhuraju, P. and Becker, K. (2003). Studies on the in vitro starch digestibility and the glycemic index of six different indigenous rice cultivars from the Philippines. Food Chemistry, 83(3), 395-402. https://doi.org/10.1016/S0308-8146(03)00101-8

Fu, Z. and BeMiller, J.N. (2017). Effect of hydrocolloids and salts on retrogradation of native and modified maize starch. Food Hydrocolloids, 69, 36-48. https:// doi.org/10.1016/j.foodhyd.2017.01.023

García-Ochoa, F., Santos, V.E., Casas, J.A. and Gómez, E. (2000). Xanthan gum: Production, recovery, and properties. Biotechnology Advances, 18(7), 549-579. https://doi.org/10.1016/S0734-9750(00)00050-1

Gonera, A. and Cornillon, P. (2002). Gelatinization of starch/gum/sugar systems studied by using DSC, NMR, and CSLM. Starch, 54(11), 508-516. https:// doi.org/10.1002/1521-379X(200211)

54:11<508::AID-STAR508>3.0.CO;2-K

Goñi, I., Garcia-Alonso, A. and Saura-Calixto, F. (1997). A starch hydrolysis procedure to estimate glycemic index. Nutrition Research, 17(3), 427-437. https:// doi.org/10.1016/S0271-5317(97)00010-9

Horigane, A.K., Engelaar, W.M.H.G., Toyoshima, H., Ono, H., Sakai, M., Okubo, A. and Nagata, T. (2000). Differences in hollow volumes in cooked rice grains with various amylose contents as determined by NMR micro imaging. Journal of Food Science, 65(3), 408-412. https:// doi.org/10.1111/j.1365-2621.2000.tb16017.x

Hu, J.L., Nie, S.P., Li, N., Min, F.F., Li, C., Gong, D. and Xie, M.Y. (2014). Effect of gum arabic on glucose levels and microbial short-chain fatty acid production in white rice porridge model and mixed grain porridge model. Journal of Agricultural and Food Chemistry, 62, 6408-6416. https:// doi.org/10.1021/jf501557b

Jane, J., Chen, Y.Y., Lee, L.F., McPherson, A.E., Wong, K.S., Radosavljevic, M. and Kasemsuwan, T. (1999). Effects of amylopectin branch chain length and amylose content on the gelatinization and pasting properties of starch. Cereal Chemistry, 76(5), 629-637.

https://doi.org/10.1094/

CCHEM.1999.76.5.629

Jang, H.L., Bae, I.Y. and Lee, H.G. (2015). In-vitro starch digestibility of noodles with various cereal flours and hydrocolloids. LWT - Food Science and Technology, 63(1), 122-128. https://doi.org/10.1016/ j.lwt.2015.03.029

Ji, Y., Zhu, K., Qian, H. and Zhou, H. (2007). Staling of cake prepared from rice flour and sticky rice flour. 
Food Chemistry, 104(1), 53-58. https:// doi.org/10.1016/j.foodchem.2006.10.072

Jung, D.S., Bae, I.Y., Oh, I.K., Han, S.I., Lee, S.J. and Lee, H.G. (2017). Classification of hydrocolloids based on in vitro starch digestibility and rheological properties of Segoami gel. International Journal of Biological Macromolecules, 104(Part A), 442-448. https://doi.org/10.1016/j.ijbiomac.2017.06.063

Koh, L.W., Kasapis, S., Lim, K.M. and Foo, C.W. (2009). Structural enhancement leading to retardation of in vitro digestion of rice dough in the presence of alginate. Food Hydrocolloids, 23(6), 1458-1464. j.foodhyd.2008.07.020

Li, J.M. and Nie, S.P. (2016). The functional and nutritional aspects of hydrocolloids in foods. Food Hydrocolloids, 53, 46-61. https://doi.org/10.1016/ j.foodhyd.2015.01.035

Minekus, M., Alminger, M., Alvito, P., Ballance, S., Bohn, T., Bourlieu, C., Carriere, F., Boutrou, R., Corredig, M., Dupont, D., Dufour, D., Egger, L., Golding, M., Karakayam S., Kirkhus, B., Le Feunteun, S., Lesmes, U., Macierzanka, A., Mackie, A., Marze, S., McClements, D.J., Menard, O., Recio, I., Santos, C.N., Singh, R.P., Vegarud, G.E., Wickham, M.S.J., Weitschies, W. and Brodkorb, A. (2014). A standardised static in vitro digestion method suitable for food-an international consensus. Food and Function, 5(6), 1113-1124. https:// doi.org/10.1039/c3fo60702j

Ogawa, Y., Glenn, G.M., Orts, W.J. and Wood, D.F. (2003). Histological Structures of Cooked Rice Grain. Journal of Agricultural and Food Chemistry, 51, 7019-7023. https://doi.org/10.1021/jf034758o

Perdon, A.A., Siebenmorgen, T.J., Buescher, R.W. and Gbur, E.E. (1999). Starch retrogradation and texture of cooked milled rice during storage. Journal of Food Science, 64(5), 828-832. https:// doi.org/10.1111/j.1365-2621.1999.tb15921.x

Piyawanitpong, C., Therdthai, N. and Ratphitagsanti, W. (2018). Effect of precooking and superheated steam treatment on quality of black glutinous rice. Journal of Food Quality, 2018, 8496723. https:// doi.org/10.1155/2018/8496723

Ramesh, M., Zakiuddin-Ali, S. and Bhattacharya, K.R. (1999). Structure of rice starch and its relation to cooked-rice texture. Carbohydrate Polymers, 38(4), 337-347. https://doi.org/10.1016/S0144-8617(98) 00125-8

Ramírez, C., Millon, C., Nuñez, H., Pinto, M., Valencia, P., Acevedo, C. and Simpson, R. (2015). Study of effect of sodium alginate on potato starch digestibility during in vitro digestion. Food Hydrocolloids, 44, 328-332. https://doi.org/10.1016/ j.foodhyd.2014.08.023

Roberts, K.T. (2011). The physiological and rheological effects of foods supplemented with guar gum. Food Research International, 44(5), 1109-1114. https:// doi.org/10.1016/j.foodres.2011.01.065

Shi, Y.C. and Seib, P.A. (1992). The structure of four waxy starches related to gelatinization and retrogradation. Carbohydrate Research, 227, 131145. https://doi.org/10.1016/0008-6215(92)85066-9

Srikaeo, K., Furst, J., Ashton, J. and Hosken, R. (2006). Microstructural changes of starch in cooked wheat grains as affected by cooking temperatures and times. LWT-Food Science and Technology, 39(5), 528-533. https://doi.org/10.1016/j.lwt.2005.04.004

Srikaeo, K., Laothongsan, P. and Lerdluksamee, C. (2018). Effects of gums on physical properties, microstructure and starch digestibility of driednatural fermented rice noodles. International Journal of Biological Macromolecules, 109, 517-523. https:// doi.org/10.1016/j.ijbiomac.2017.12.121

Turabi, E., Sumnu, G. and Sahin, S. (2008). Rheological properties and quality of rice cakes formulated with different gums and an emulsifier blend. Food Hydrocolloids, 22(2), 305-312. https:// doi.org/10.1016/j.foodhyd.2006.11.016

Viebke, C., Al-Assaf, S. and Phillips, G.O. (2014). Food hydrocolloids and health claims. Bioactive Carbohydrates and Dietary Fibre, 4(2), 101-114. https://doi.org/10.1016/j.bcdf.2014.06.006

Villareal, C.P., Hizukuri, S. and Juliano, B.O. (1997). Amylopectin staling of cooked milled rices and properties of amylopectin and amylose. Cereal Chemistry, 74(2), 163-167. https://doi.org/10.1094/ CCHEM.1997.74.2.163

Zhou, Y., Wang, D., Zhang, L., Du, X. and Zhou, X. (2008). Effect of polysaccharides on gelatinization and retrogradation of wheat starch. Food Hydrocolloids, 22(4), 505-512. https:// doi.org/10.1016/j.foodhyd.2007.01.010

Zhu, L.J., Liu, Q.Q., Sang, Y., Gu, M.H. and Shi, Y.C. (2010). Underlying reasons for waxy rice flours having different pasting properties. Food Chemistry, 120(1), 94-100. https://doi.org/10.1016/ j.foodchem.2009.09.076 